\title{
Tandem duplications of two separate fragments of the dystrophin gene in a patient with Duchenne muscular dystrophy
}

\author{
Zhujun Zhang $\cdot$ Yasuhiro Takeshima $\cdot$ \\ Hiroyuki Awano $\cdot$ Atsushi Nishiyama \\ Yo Okizuka $\cdot$ Mariko Yagi $\cdot$ Masafumi Matsuo
}

Received: 7 November 2007/ Accepted: 3 December 2007/Published online: 27 December 2007

(C) The Japan Society of Human Genetics and Springer 2007

\begin{abstract}
Mutations in the dystrophin gene result in the most common inherited muscle disease, Duchenne muscular dystrophy (DMD). Duplications spanning one or more exons have been found to be the second most common disease-causing mutation in the dystrophin gene. Although the duplicated exons are commonly thought to be arranged in tandem, rare noncontiguous exon duplications have been disclosed without clarifying their location or orientation. Here we present the first report that details the exact locations and orientations of noncontiguous duplications in the dystrophin gene. Multiplex ligationdependent probe amplification analysis of the dystrophin gene of a Japanese boy with DMD revealed that his genomic DNA contained duplications of exons from two separate fragments of the gene: one from exon 45 to exon 48 and the other from exon 55 to exon 63 . To clarify the locations and orientations of the duplicated exons, reverse transcription-nested PCR analysis of dystrophin mRNA was conducted. Interestingly, the extra copies of exons 4548 and exons 55-63 were found to be properly oriented between exons 48 and 49 and exons 63 and 64, respectively. These results indicated that two tandem duplication events occurred in the dystrophin gene of this patient and should contribute to the understanding of the duplication mechanisms that contribute to the development of DMD.
\end{abstract}

Keywords Dystrophin · Mutation · Duplication

\footnotetext{
Z. Zhang $\cdot$ Y. Takeshima $\cdot$ H. Awano $\cdot$ A. Nishiyama

Y. Okizuka · M. Yagi · M. Matsuo ( $\square)$

Department of Pediatrics, Graduate School of Medicine Kobe University, 7-5-1 Kusunokicho, Chuo, Kobe 650-0017, Japan

e-mail: matsuo@kobe-u.ac.jp
}

\section{Introduction}

Duchenne muscular dystrophy (DMD) is the most common inherited muscle disease, affecting 1 in every 3,500 male births. This disease is caused by mutations in the dystrophin gene located on $\mathrm{Xp} 21$. Deletions involving one or more exons are the most common type of mutation associated with DMD, accounting for nearly two-thirds of all cases. Duplications are the second most common type of mutation in this gene, occurring in approximately $5-10 \%$ of DMD patients (Hu et al. 1990; White et al. 2002, 2006).

Because the dystrophin gene consists of 79 exons spanning more than $2,500 \mathrm{~kb}$ in the human genome, it has been difficult to examine every exon for deletions or duplications. Instead, PCR amplification of deletion-prone exons has been used to genetically diagnosis patients suspected of having DMD (Chamberlain et al. 1988; Beggs et al. 1990). Recently, multiplex ligation-dependent probe amplification (MLPA) analysis, which is used to examine every exon for deletion and/or duplications, has been developed, resulting in a marked improvement in the mutation detection rate (Janssen et al. 2005).

Interestingly, MLPA analysis produced ambiguous results in eight cases in whom twice as much genomic DNA was detected for two separate fragments of the dystrophin gene (Janssen et al. 2005; White et al. 2006; Zeng et al. 2007). Although these cases are thought to carry tandem duplications of two separate dystrophin gene fragments, details of the duplicated exon fragments have not been reported, thereby making it possible that the extra genomic fragments were located outside of the dystrophin gene. In this article, we describe a patient with novel noncontiguous duplications in his dystrophin gene; detailed mRNA analysis revealed tandem duplication of two separate fragments from this gene. 


\section{Case and methods}

Case

More than 400 DMD patients at the Kobe University Hospital were subjected to mutation analysis of their dystrophin genes. Among these patients, 27 cases were shown to carry duplications of contiguous exons. Recently, one case was found to have noncontiguous duplications. The proband (KUCG759) was a 5-year-old boy. At 1 year old, his serum creatine kinase (CK) level was found to be markedly elevated (12,320-17,712 IU/1), and a muscle biopsy disclosed no dystrophin-specific staining, confirming a diagnosis of DMD. At 4 years old, the patient's Gowers' sign was positive, and he was referred to our hospital for an examination of his dystrophin gene. The Ethics Committee of the Kobe University Graduate School of Medicine approved this study, and consent was obtained from his parents.

MLPA analysis

DNA was isolated from lymphocytes obtained from the patient and normal individuals using standard phenol- chloroform extraction methods. MLPA was performed with the P034 and P035 kits from MRC-Holland (Amsterdam, The Netherlands) as described (Lalic et al. 2005). This technique allowed the full dystrophin gene to be examined for any deletions or duplications.

Polymorphism analysis

To characterize the duplicated fragments, genomic regions encompassing each set of duplicated exons were amplified using primers specific for the flanking sequences (Table 1), resulting in the amplification of dinucleotide repeat markers from intron 45 (STR-45) and intron 62 (DI623) (Clemens et al. 1991). Amplified products were directly sequenced using an automated DNA sequencer (model 310; Applied Biosystems, Foster City, CA).

Analysis of dystrophin mRNA

The dystrophin mRNA expressed in lymphocytes was examined by reverse transcription (RT)-nested PCR

Table 1 Primer sequence

\begin{tabular}{|c|c|c|}
\hline Target region & Forward primer & Reverse primer \\
\hline \multicolumn{3}{|l|}{ gDNA } \\
\hline Exon 45 & $5^{\prime}$ TGCCAGTACAACTGCATGTGGTAG 3' & $5^{\prime}$ GCTTATAATCTCTCATGAAATATTC 3 \\
\hline Exon 46 & 5' GTTTGTGTCCCAGTTTGCATTAAC 3' & $5^{\prime}$ GGCAGAAAACCAATGATTGAATTA $3^{\prime}$ \\
\hline Exon 47 & $5^{\prime}$ GGGGTGAGTGTTTCAGTCAATC $3^{\prime}$ & $5^{\prime}$ CATATAGCCAAAGCAAACGGTC $3^{\prime}$ \\
\hline Exon 48 & $5^{\prime}$ TAAACATTTTGGCTTATGCCTTGA $3^{\prime}$ & $5^{\prime}$ TGGTGCCTGTGCCTATTGTGTTAT $3^{\prime}$ \\
\hline Exon 55 & $5^{\prime}$ CCATCTTTCTCTTTTTATGGAGTT $3^{\prime}$ & $5^{\prime}$ TTGTCCCTGGCTTGTCAGTT $3^{\prime}$ \\
\hline Exon 56 & $5^{\prime}$ TACGCCAAGAAAAGGGATTTGAGA $3^{\prime}$ & $5^{\prime}$ CCAGTTACTTGTGCTAAGACAATGAGG $3^{\prime}$ \\
\hline Exon 57 & $5^{\prime}$ ACACTTCTAGATATTCTGACATGG $3^{\prime}$ & $5^{\prime}$ GTCACTGGATTACTATGTGCTTAAC $3^{\prime}$ \\
\hline Exon 58 & $5^{\prime}$ GCACCCAGGATTAATTTTGAGAAGA 3' & $5^{\prime}$ CCAGACCCTGGCAGCAAGAAT $3^{\prime}$ \\
\hline Exon 59 & $5^{\prime}$ CAGTAGGTTACCCTCTTGTTCAAC $3^{\prime}$ & $5^{\prime}$ GGGAAGATAACACTGCACTCAAGT $3^{\prime}$ \\
\hline Exon 60 & $5^{\prime}$ CCCTAAAGAGAATAAGCCCAGGTA $3^{\prime}$ & $5^{\prime}$ TCCTATCCTCACAAATATTACCATGAA $3^{\prime}$ \\
\hline Exon 61 & 5' GTTGCTTTAGTGTTCTCAGTCTTGGA 3' & $5^{\prime}$ GGATGATTTATGCTTCTACTGCTACTG $3^{\prime}$ \\
\hline Exon 62 & $5^{\prime}$ CCTGTTTGCGATGAATTTGACCTC $3^{\prime}$ & $5^{\prime}$ ACAGGTTAGTCACAATAAATGCTCTT $3^{\prime}$ \\
\hline Exon 63 & $5^{\prime}$ GCAAAAATCATGTTGTTGTTATTG $3^{\prime}$ & $5^{\prime}$ CAAGTAACTTTCACACTGCAAACT $3^{\prime}$ \\
\hline Intron 45 & $5^{\prime}$ GAGGCTATAATTCTTTAACTTTGGC $3^{\prime}$ & $5^{\prime}$ СТCTTTCССТCTTTATTCATGTTAC $3^{\prime}$ \\
\hline Intron 62 & $5^{\prime}$ ACCTGCCTAGTCAAGGTA $3^{\prime}$ & $5^{\prime}$ CACTGCCATGGTGAATGATC $3^{\prime}$ \\
\hline \multicolumn{3}{|l|}{ mRNA } \\
\hline Exon 44 & 4A: $5^{\prime}$ TGGCGGCGTTTTCATTAT $3^{\prime}$ & \\
\hline Exon 46 & & c46r: 5' CTTGACTTGCTCAAGCTTTTC $3^{\prime}$ \\
\hline Exon 47 & c47f: 5' TTACTGGTGGAAGAGTTG 3' & \\
\hline Exon 52 & & 4D: $5^{\prime}$ CGATCCGTAATGATTGTTCTAGC $3^{\prime}$ \\
\hline \multirow[t]{2}{*}{ Exon 59} & & 4B: $5^{\prime}$ CGGAGTGCAGGTTCAATTTT $3^{\prime}$ \\
\hline & & 4F: 5' CCCACTCAGTATTGACCTCCTC $3^{\prime}$ \\
\hline Exon 60 & c60f: $5^{\prime}$ TCAGCACTCTGGAAGACCTG $3^{\prime}$ & \\
\hline Exon 61 & c61f: 5' GCCGTCGAGGACCGAGTCAGGCAGCT 3' & \\
\hline
\end{tabular}


analysis as described previously (Matsuo et al. 1991). Briefly, total RNA was isolated from peripheral lymphocytes, and cDNA was synthesized. A fragment encompassing the duplicated region of exons $45-48$ was amplified using an outer set of primers with a forward primer corresponding to a segment of exon 44 and a reverse primer complementary to a segment of exon 52 . The PCR product was then used as a template for a second PCR using an inner set of primers with a forward primer specific for exon 47 and a reverse primer complementary to exon 46 (Table 1). A fragment encompassing the duplicated region of exons 55-63 was also amplified using two sets of primers: an outer set with a forward primer specific for exon 60 and a reverse primer complementary to exon
59 and an inner set with a forward primer specific for exon 61 and a reverse primer complementary to exon 59 (Table 1). The amplified products were purified and directly sequenced.

\section{Results}

MLPA analysis of the dystrophin gene in the index patient disclosed that all of the exons were present. For a total of 13 exons, however, the signals resulting from MLPA analysis were twice those observed in samples from a normal male control subject, indicating that these exons were duplicated (Fig. 1). Surprisingly, these 13 exons were

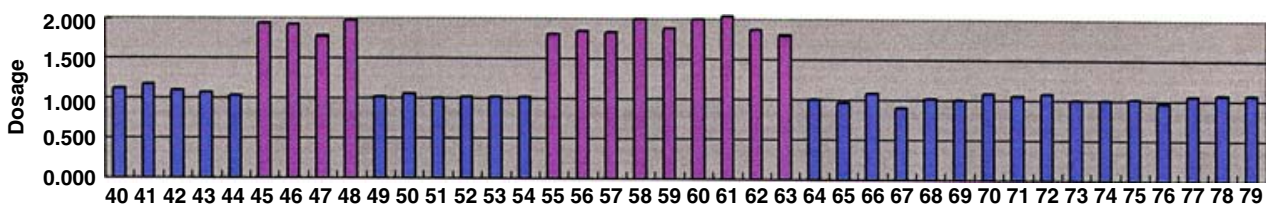

Fig. 1 MLPA analysis of the dystrophin gene. Bars represent the amount of amplified product expressed as a ratio to the results obtained with a control sample. Numbers below the bars indicate the exon numbers. The heights of the bars represent the relative signals of the corresponding exons compared to those obtained from a male control sample. Exons 45-48 and exons 55-63 produced signals that were twice those obtained for the other exons

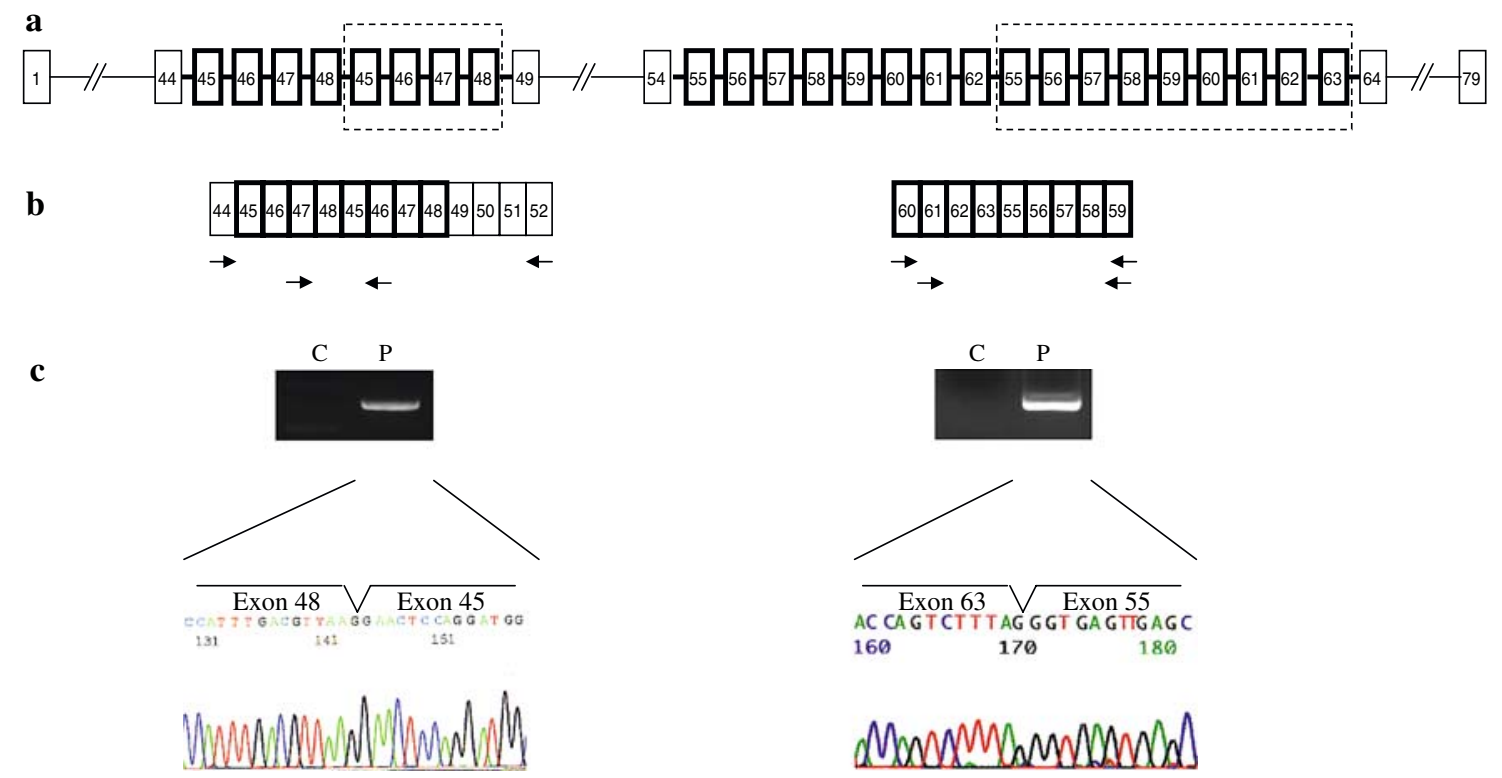

Fig. 2 RT-PCR amplification of the duplication borders of exons 4548 and exons 55-63. a The predicted genomic structure of the duplicated region of the dystrophin gene. The boxes represent exons and the numbers in the boxes indicate the exon numbers. Horizontal lines between the boxes indicate introns. Duplicated fragments have been denoted with dotted lines. b The predicted fragments of the dystrophin transcripts covering the two duplicated regions. Boxes represent exons, and horizontal arrows show the locations and orientations of the outer and inner primers that were used for RT-PCR analysis. c RT-PCR products for the index patient $(P)$ and a control subject $(C)$ encompassing the duplication breakpoints. PCR products were visualized on a gel (top panel). No amplified product was obtained from the control sample, whereas the index case produced a clear band. A partial sequence of the amplified product is shown (bottom panel); the $3^{\prime}$ terminal sequence of exon 48 is joined to the $5^{\prime}$ end of exon 45, and the $3^{\prime}$ end of exon 63 is joined to the $5^{\prime}$ end of exon 55 
clustered in two separated regions of the dystrophin gene: one extending from exon 45 to exon 48 and the other spanning from exon 55 to exon 63. Normal signal levels were observed for exons 49-54 located between the two duplicated regions, indicating that these exons were present as single copies. Although duplications of exons in the dystrophin gene are commonly thought to occur in tandem, the locations and orientations of the two duplicated fragments were unclear.

To determine the exact location as well as the orientations of the duplicated exons, dystrophin mRNA from lymphocytes was analyzed using RT-nested PCR amplifications. When we amplified a fragment extending from exon 47 to exon 46, a product was obtained from the index case, but not from the control subject. Direct sequencing of the product disclosed the sequences of exons $47,48,45$, and 46 , revealing that the $3^{\prime}$ end of exon 48 was directly joined to the $5^{\prime}$ end of exon 45 (Fig. 2). Similarly, a fragment extending from exon 61 to exon 59 was only amplified from the index case, but not from the control subject. Sequencing of the product revealed that the $3^{\prime}$ end of exon 63 was directly joined to the $5^{\prime}$ end of exon 55 (Fig. 2). Sequences of the other portions of the dystrophin mRNA from the index case, including from exon 55 to exon 63, were the same as was observed in the control sample (data not shown). According to the reading frame rule, the more $3^{\prime}$ duplication of exons 55-63 disrupted the reading frame of the patient's dystrophin mRNA, resulting in a severe DMD phenotype. Our mRNA analysis disclosed that each exon duplicated in his dystrophin gene was incorporated into the fully spliced mRNA and that both of the duplicated fragments were present in tandem to their respective fragment.

To identify the source of the two duplicated fragments, all of the duplicated exons were sequenced, and polymorphic markers in introns 45 and 62 were also analyzed. No heterozygosities, however, were disclosed in the exon sequences (data not shown). Moreover, no differences were observed for markers in introns 45 and 62, at which heterozygosities have been reported. This suggests that both duplicated fragments were derived from the same chromosome.

\section{Discussion}

We have previously identified 27 subjects with duplication mutations in their dystrophin genes, all of which were contiguous. In this study, we report a novel case carrying noncontiguous duplications in the dystrophin gene; two separate fragments from exon 45 to exon 48 and from exon 55 to exon 63 were duplicated. The index case is the first reported Japanese case with noncontiguous duplications in the dystrophin gene.

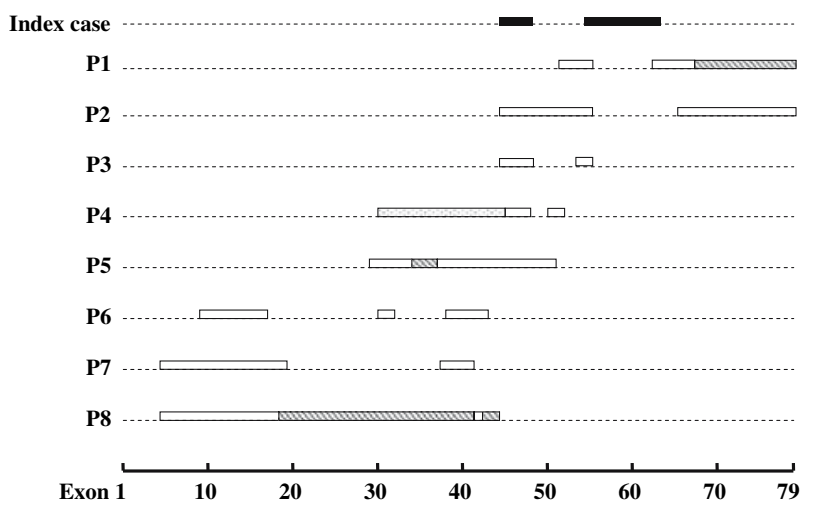

Fig. 3 A schematic representation of the distribution of identified noncontiguous duplications in the dystrophin gene. Horizontal bars indicate duplicated regions that have been identified in patients with DMD. The black bars indicate duplications identified in this study, and the unfilled bars indicate previously $(P)$ reported cases of noncontiguous duplications. The shaded and dotted bars denoted previously reported partial triplications and a partial quadruplication, respectively

MLPA analysis only demonstrates changes in the copy number of individual exons, and it is difficult to know the exact organization of the duplicated exons. Duplications can result in transpositions, which would have no effect on the reading frame if the duplicated regions are inserted outside of the dystrophin gene (White et al. 2006). Several examples of such transposition events have been described for the gene encoding proteolipid protein 1 ( $P L P 1)$, in which an additional copy of $P L P 1$ gene was found integrated at noncontiguous sites on the X chromosome (Xp22 and Xq26) (Woodward et al. 2005). Though eight noncontiguous duplications, three of which involved partial triplications or a quadruplication, have been previously identified in the dystrophin gene (Janssen et al. 2005; White et al. 2006; Zeng et al. 2007), there are no descriptions of the locations and orientations of the duplications. Our results indicated that both of the duplications in the index case were inserted in tandem and maintained the same orientation as that of the dystrophin gene. This provides the first evidence for the tandem organization of duplications in the dystrophin gene.

Our case is the ninth reported patient with noncontiguous duplications in the dystrophin gene. Although the majority of the reported duplications have clustered toward the $5^{\prime}$ end of the dystrophin gene (White et al. 2006), the distribution of noncontiguous duplications is shifted slightly toward the $3^{\prime}$ end of the gene: four, two, and three of the duplications were located in the $3^{\prime}$ portion, in the middle, and in the $5^{\prime}$ portion of the dystrophin gene, respectively (Fig. 3). Eight of the nine duplications were located in major (exons 45-52) and minor (exons 3-19) deletion hot spots. In particular, four noncontiguous duplications had breakpoints in intron 44 , whereas three 
had breakpoints in intron 55. The extraordinary size of intron $44(250 \mathrm{~kb})$ and intron $55(120 \mathrm{~kb})$ are likely to make these two introns prone to rearrangement and recombination events that result in duplications.

What was the source of the duplicated exons? Because the duplicated alleles showed no nucleotide differences (data not shown), they likely arose as a result of an interchromosomal event. It has been reported that unequal crossing over between sister chromatids, rather than between nonsister chromatids from two $\mathrm{X}$ chromosomes, is the predominant cause of duplications in the dystrophin gene ( $\mathrm{Hu}$ et al. 1991). Another possible mechanism that may generate a duplication is synthesis-dependent nonhomologous end joining (Helleday 2003). This process results in a tandem duplication at the site of a double-stranded break, and unequal crossing over does not take place. This mechanism has recently been proposed for a duplication of exon 2 in the dystrophin gene and PLPl (White et al. 2006). Whether this mechanism is involved in the formation of noncontiguous duplications, however, is unclear. Further refinement of the duplication breakpoint will enable us to understand the mechanism underlying the rearrangement.

In conclusion, we identified novel noncontiguous duplications in the dystrophin gene of a patient with DMD. Detailed RNA analysis confirmed that the RNA in fact did contain two duplications. In addition, we were able to show that both of the noncontiguous duplications were organized in tandem, which provides insight into the mutational mechanisms that cause noncontiguous duplications.

Acknowledgments We would like to thank Ms. Inagawa for her secretarial help. This work was supported by a grant-in-aid for scientific research from the Japan Society for the Promotion of Science; Health and Labor Sciences Research Grants for Research on Psychiatric and Neurological Diseases and Mental Health; a research grant for nervous and mental disorders from the Ministry of Health, Labor, and Welfare; and the Mitsubishi Foundation.

\section{References}

Beggs AH, Koenig M, Boyce FM, Kunkel LM (1990) Detection of $98 \%$ of DMD/BMD gene deletions by polymerase chain reaction. Hum Genet 86:45-48
Chamberlain JS, Gibbs RA, Ranier JE, Nguyen PN, Caskey CT (1988) Deletion screening of the Duchenne muscular dystrophy locus via multiplex DNA amplification. Nucleic Acids Res 16:11141-11156

Clemens P, Fenwick R, Chamberlain J, Gibbs R, de Andrade M, Chakraborty R, Caskey C (1991) Carrier detection and prenatal diagnosis in Duchenne and Becker muscular dystrophy families, using dinucleotide repeat polymorphisms. Am J Med Genet 49:951-960

Helleday T (2003) Pathways for mitotic homologous recombination in mammalian cells. Mutat Res 532:103-115

Hu XY, Ray PN, Murphy EG, Thompson MW, Worton RG (1990) Duplicational mutation at the Duchenne muscular dystrophy locus: its frequency, distribution, origin, and phenotypegenotype correlation. Am J Hum Genet 46:682-695

Hu XY, Ray PN, Worton RG (1991) Mechanisms of tandem duplication in the Duchenne muscular dystrophy gene include both homologous and nonhomologous intrachromosomal recombination. Embo J 10:2471-2477

Janssen B, Hartmann C, Scholz V, Jauch A, Zschocke J (2005) MLPA analysis for the detection of deletions, duplications and complex rearrangements in the dystrophin gene: potential and pitfalls. Neurogenetics 6:29-35

Lalic T, Vossen R, Coffa J, Schouten J, Guc-Scekic M, Radivojevic D, Djurisic M, Breuning M, White SdDJ (2005) Deletion and duplication screening in the DMD gene using MLPA. Eur J Hum Genet 13:1231-1234

Matsuo M, Masumura T, Nishio H, Nakajima T, Kitoh Y, Takumi T, Koga J, Nakamura H (1991) Exon skipping during splicing of dystrophin mRNA precursor due to an intraexon deletion in the dystrophin gene of Duchenne muscular dystrophy Kobe. J Clin Invest 87:2127-2131

White S, Kalf M, Liu Q, Villerius M, Engelsma D, Kriek M, Vollebregt E, Bakker B, van Ommen GJ, Breuning MH, den Dunnen JT (2002) Comprehensive detection of genomic duplications and deletions in the DMD gene, by use of multiplex amplifiable probe hybridization. Am J Hum Genet 71:365-374

White SJ, Aartsma-Rus A, Flanigan KM, Weiss RB, Kneppers AL, Lalic T, Janson AA, Ginjaar HB, Breuning MH, den Dunnen JT (2006) Duplications in the DMD gene. Hum Mutat 27:938-945

Woodward KJ, Cundall M, Sperle K, Sistermens EA, Ross M, Howell G, Gribble SM, Burford DC, Carter NP, Hobson DL, Garbem JY, Kamholz J, Heng H, Hodes ME, Malcolm S, Hobson GM (2005) Heterogeneous duplications in patients with PelizaeusMerzbacher disease suggest a mechanism of coupled homologous and nonhomologous recombination. Am J Hum Genet 77:966-987

Zeng F, Ren ZR, Huang SZ, Kalf M, Mommersteeg M, Smit M, White S, Jin CL, Xu M, Zhou DW, Yan JB, Chen MJ, van Beuningen R, Huang SZ, den Dunnen J, Zeng YT, Wu Y (2007) Array-MLPA: comprehensive detection of deletions and duplications and its application to DMD patients. Hum Mutat 13 Sep (Epub ahead of print) 